\title{
A Preliminary Study on the Chinese Documents with the Reign Title Unearthed in Khara-Khoto
}

\author{
Xiaoming Li \\ Wuwei Museum \\ Wuwei, China 733000
}

\begin{abstract}
Khara-Khoto is unearthed Chinese literatures, which are accompanied by a large number of social documents with the reign titles. And these reign titles are of great significance on determining the date of the document and researching the relevant historical background. This paper sketches the source, age, paintings origin and corresponding contents of these instruments in order to provide some convenience for researching and arranging the literature unearthed in Khara-Khoto.
\end{abstract}

Keywords-Khara-Khoto; Chinese literatures; reign titles; hand-copied books

\section{INTRODUCTION}

The discovery of the Khara-Khoto document is considered to be the third largest archaeological discovery in China following the Oracle Boon in Yin Ruins and the Dunhuang Posthumous Writings in the late 19th and early 20th centuries. In recent decades, with the massive publication of KharaKhoto literatures, ${ }^{1}$ the academic circles' research on relevant subjects, such as Study of Xixia and Study of Khara-Khoto, has been flourishing.

The literature relics unearthed in the site of Back Water City are mainly collected in relevant institutions of Russia, the United Kingdom, and China. In recent years, these unearthed relics have been managed and published. The excavation,

Institute of Archaeology of Inner Mongolia Autonomous Region, Xixia Research Center of Ningxia University, and Gansu Provincial Archives Compilation Center for Ancient Books. Chinese Archives of Khara-Khoto in China[M]. Beijing: National Library Press, 2008; St. Petersburg Branch of the Institute of Oriental Studies of Russian Academy of Sciences, Institute of Nationalities of China Academy of Social Sciences, Shanghai Ancient Books Publishing House, Literatures of Khara-Khoto in Russia[M]. Shanghai: Shanghai Ancient Books Publishing House, 1996; British National Library, Second Nationalities College of Northwest China, Shanghai Ancient Books Publishing House. [M]. Literatures of Khara-Khoto in Britain[M]. Shanghai: Shanghai Ancient Books Publishing House 2005-2010; Sa Zhi, Wu Fangsi. Chinese literature (non-Buddhism) obtained by Stein in the third Central Asian archaeology [M]. Shanghai: Shanghai Lexicographical Publishing House 2005; St. Petersburg Branch of the Institute of Oriental Studies of Russian Academy of Sciences, Oriental Literature Department of Russian Literature Press, Shanghai Ancient Books Publishing House, Dunhuang Literature Collection in Russian [M]. Shanghai: Hai Ancient Books Publishing House 1992-2001; Russian National Hermitage Museum, Northwest University for Nationalities, Shanghai Ancient Books Publishing House. Artwork Collection of Khara-Khoto in Russia [M]. Shanghai: Shanghai Ancient Books Publishing House 2008. collection and publication situation of these documents are as follows:

The discovery of the Khara-Khoto literature began in 1908 and 1909 with the cultural artifacts excavated by the Russian soldier Kirslov twice in Khara-Khoto. These cultural relics were divided into non-literature and literature. Not only the literatures were the firstly-discovered batch in the KharaKhoto, but also the collections of more valuable than most of others and the batch of largest number in foreign countries. Among them, the none-literature part is currently collected in the Russian National Hermitage Museum, and the literature part is currently in the St. Petersburg branch of the Institute of Oriental Studies of the Russian Academy of Sciences. From 1996 to 2007, St. Petersburg branch of the Institute of Oriental Studies of the Russian Academy of Sciences, Chinese National Academy of Social Sciences Research Institute and the Shanghai ancient books publishing house have consecutively published the "Russian Stored Khara-Khoto Literature " of total 13 volumes, which consist of a large number of Chinese and Xixia documents reserved in Russia. In 2008, Russian National Hermitage Museum, Northwest Minzu University and Shanghai Ancient Books Publishing House jointly published the "Russian Stored Khara-Khoto Artwork ", which consist of some relic artworks unearthed in Khara-Khoto. In addition, in the period from 1992 to 2001 , the 17 volumes of "Russian Stored Dunhuang Literature " published by the St. Petersburg Office of the Oriental Institute of the Russian Academy of Sciences, the Oriental Literature Department of the Russian Science Press, and the Shanghai Ancient Books Publishing House were also mixed by some Khara-Khoto documents.

In 1914, the British explorer Stein also went to KharaKhoto to collect a large number of documentary relics, of which the part of the Khara-Khoto literature now houses the British National Library. In 2005, the Shanghai Dictionary Publishing House published the Chinese literature of Stein Third Central Asian Archaeology (part of the non Buddhist Scriptures) edited by Sha Zhi and Wu Fangsi, which contains more than 200 documentary scraps collected by Stein in the Khara-Khoto area. From 2005 to 2010, the 1-5 volumes of the "British Stored Water City Documentary" edited by the British National Library, the Second Northwestern Minzu College, and the Shanghai Ancient Books Publishing House were successively published. In this work, the Xixia literature of Khara-Khoto and a small amount of Chinese literature reversed in the British National Library are collected and it is 
another important work from Khara-Khoto about the study of Xixia literature.

In 1927, in the northwestern archaeological activity carried out by Northwest China Scientific Investigation Group organized by China and Sweden, Mr. Huang Wenbi also collected hundreds of documents in the Khara-Khoto area, which is currently possessed by the Institute of Archaeology of the Chinese Academy of Social Sciences. ${ }^{2}$

In China, in recent decades, archaeological excavations have also been carried out on the site of the Khara-Khoto and a large number of documents and cultural relics have been obtained. In 1962 and 1963, when the Inner Mongolia Autonomous Region cultural relic brigade investigated the ancient Juyan area, they collected a small amount of documents in the Khara-Khoto, and the documents are now stored in the Inner Mongolia Museum. In 1976 and 1979, the Gansu Provincial Cultural Relics brigade visited Khara-Khoto twice and collected a small number of documents, which are now stored in the Gansu Provincial Museum. Mr. Chen Bingying once studied and interpreted the part of Chinese documents reserved in Gansu Province and unearthed in Khara-Khoto. ${ }^{3}$

In 1983 and 1984, the Research Institute of Cultural Relics Archaeology of Inner Mongolia Autonomous Region and Alashan Cultural Relics workstations jointly conducted a large-scale archaeological excavation in Khara-Khoto site and unearthed nearly more than 3000 documents. Based on these documents, in 2008, the Inner Mongolia Autonomous Region Archaeological Research Institute, Xixia research center of Ningxia University and Gansu Ancient Book Compilation center collaboratively published the China Reserved KharaKhoto Literature compiled by Tara, Du Jianlu and Gao Guoxiang. This is an important work for the study of the Khara-Khoto documents and meanwhile, it is a masterpiece that has the Khara-Khoto literatures collection at most.

\section{DISCUSSION ON THE RELATED PROBLEMS OF CHINESE DOCUMENTS WITH REIGN TITLE UNEARTHED IN KHARA- КнотО}

The above documents constitute the main part of the documents unearthed in Khara-Khoto that are currently being studied by the academic community. And these documents are rich in content and of great value. The documents are involved in Tang, Song, Liao, Jin, pseudo Qi, Xixia, Yuan, and other political times while the contents of the document include various National characters, such as Chinese, Xixia characters, Huihu characters, Mongolian, Phags-pa Mongolian, ancient Tibetan, 1stifa', Arabic ,Sanskrit and so non.

\footnotetext{
2 Zhang Guowang, A Survey of Chinese Documents of the Yuan Dynasty Unearthed in the Hei City [J]. Khara-Khoto's Humanities and Environment Research - International Symposium on Khara-Khoto's Humanities and Environment, Beijing: China Renmin University Press 2007, Page 625-633; Du Jianlu, Khara-Khoto's Chinese Literature Review, the 4th Tangutology, July 2009. pp 3-14.

Chen Bingying, A Series of Yuan Dynasty Instruments Unearthed in the Hei City[J], Cultural Relics and Archaeology 1983, the 1st , pp 55-62
}

On the basis of the rough statistics of relevant publications and researches literature, the number of Chinese documents unearthed in Khara-Khoto is as follows: there are about 4213 pieces of China stored Chinese documents unearthed in KharaKhoto while the number of Russia stored documents is 488 pieces according to Lev Nikolaevich Menshikov's data. ${ }^{4}$ In the Chinese literature (non Buddhist Scriptures) obtained in the Stein's third Central Asian Archaeology (non Buddhist Scriptures), there are 226 pieces of them that come from Khara-Khoto. The Dunhuang Manuscripts of Russian-Tibetan Collection, after the study of the Fu Xianzhan, Jin Qiankun, and Rong Xinjiang, there are at least 108 Khara-Khoto documents mixed in Russia stored Dunhuang literature and these literatures have been published. ${ }^{5}$ In the British stored literature of the Khara-Khoto, there are about 118 Chinese documents that have been mixed into the Xixia literature for a long time. After reviewing and researching a small number of literatures collected in Khara-Khoto in 1976 and 1979 by Gansu Province Cultural Relics brigade, Mr. Chen Bingying published 24 pieces of Chinese documents of Yuan Dynasty. The number of these documents is relatively conservative. With the subsequent discovery and research of Chinese documents unearthed in Khara-Khoto, the relevant literatures and documents are bond to increase.

So many documents unearthed in Khara-Khoto are attached by reign titles and time that are widely used in various kinds of documents, such as Xixia character, Chinese character. These reign titles of these documents are of great significance on determining documents' time and researching the relevant historical background. What we want to discuss here are some of the features of the Khara-Khoto documents with reign titles, which have been widely studied in the academic world.

\section{A. The Research on the Number of Documents of Khara- \\ Khoto with Reign Titles, Band Their Ages Attribution, and the Corresponding Record of the Source.}

According to conservative statistics, there are about 403 pieces of Chinese documents with reign titles unearthed in Khara-Khoto. These documents are mainly included in the first six volumes of Russian Stored Khara-Khoto Literature, China Stored Khara-Khoto Chinese Literature, Chinese literature of Stein Third Central Asian Archaeology (part of the non Buddhist Scriptures), British Stored Khara-Khoto Literature, and A Newly- Unearthed Batch of Yuan Dynasty Documents in Khara-Khoto. In addition, a part of the Khara-Khoto documents have been mixed in the Russia stored Dunhuang literature. According to the times of the regime, it was distributed as follows: 3 pieces in the Tang Dynasty, 1 piece in the Liao Dynasty, 55 in the Northern Song Dynasty, 28 in the

\footnotetext{
4 Du Jianlu, Summary of Khara-Khoto's Chinese Literature" [J], the 4th Tangutology. July, 2009, pp3-14.

Fu Xianzhan, The " Differentiation Record on Dunhuang Literature" [J], Dunhuang Research, 1996, the 2nd, pp. 84-95; Jin Yingkun, "Discussion on the Textual Research of Khara-Khoto Documents in Dunhuang Manuscripts in Russian Collections and Related Issues" [J], the 24th Dunhuang Studies, 2003, pp. 61-81; Rong Xinjiang, "The Literature of Khara-Khoto in Dunhuang Manuscripts in Russia" [J], Editor Shen Weirong, Study on Khara-Khoto's Humanities and Environment - International Symposium on Heising City's Humanities and Environment, 2007, pp 534548.
} 
Southern Song Dynasty, 3 in the Pseudo-Qi, 48 pieces in the Xixia, and 13 pieces in the Mongolia (several documents in Zhiyuan can not be identified whether they belong to proZhiyuan or post-Zhiyuan, and they are listed as the ones of pro-Zhiyuan currently), 231 pieces in Yuan Dynasty and 20 pieces in Northern Yuan Dynasty.

A concrete manifestation of this regime and the reign of documents involved are as follows: Tang Dynasty: Yongtai, Jianzhong, Zhenyuan. Liao Dynasty: Tonghe. The Northern Song Dynasty: Taiping Xingguo, Duanhong, Dazhong Xiangfu, Tiansheng, Yuanfeng, Yuanyou, Shaosheng, Chongning, Zhenghe, Xuanhe, Jingkang. The Southern Song Dynasty: Jianyan, Chunxi, Jiading. Pseudo-Qi Dynasty: Fuchang. Xixia: Tianci, Lisheng, Guoqing, Daan, Renqing, Tiansheng, Qianyou, Tianqing, Huangjian, Guangding. Mongolia Yuan Dynasty: Zhiyuan. Yuan: Dade, Zhida, Huangqing, Yanyou, Zhizhi, Taiding, Tianli, Zhishun, Yuantong, Zhiyuan, Zhizheng. The Northern Danysty: Zhizheng, Xuanguang, which are total of 450 reign titles. In addition, there is a piece of document of unknown reign title.

Academics generally believe that the upper limit of KharaKhoto's Chinese literature is the sixth year of Jianzhong of Tang Dynasty (A.D.785), and the lower limit is the Second Year of Xuanguang of Northern Yuan (A.D.1372), which spans nearly 600 years. The literatures are related to different era and regimes, including Tang, Liao and Northern Song, Southern Song, Xixia and Jin, Pseudo-Qi, Mongolia, Yuan and Northern Yuan. However, the actual upper limit of the documents unearthed in Khara-Khoto should be the second year of Yongtai of Tang Dynasty (A.D.766). This corresponding document came from the British stored KharaKhoto literature, namely "the tail of Surun Country official document in the June of the second year of Yongtai of Tang." In the past, academics had doubts about whether or not the documents came from Khara-Khoto. ${ }^{6}$ However, before there is any definite evidence, this document should still be studied as an unearthed one in Khara-Khoto. Moreover, Stein used a more rigorous scientific archeological method when collecting literature in the Khara-Khoto area. From the perspective of the British stored code, for the books coded by "OR.8212/726 KKVI.02 (a)" and recorded with "the Yongtai's second year of Tang Dynasty", KK code indicates the transliterated abbreviation of Mongolian Khara-Khoto- "Khara Khoto" and the Roman numerals of means that the documents were unearthed in a mosque in the southwest of the city. Combined with the situation of Khara-Khoto, it can be said that although the contents of these residual leaves are incomplete, the historical values are more credible.

\section{B. Discussion on the Accurate Time and Corresponding Problems of Documents with Era Name in Khara-Khoto's Chinese Literature}

First of all, from the analysis of documents' era name and annotation content, the judgments about some documents' naming and ages still need to be studied.

Xu Shenggen A Brief Account of Social Document of Heishui Literature Collected by Britain [J], Social Sciences in Ningxia No. 6, 2004 (a total of 127) Page 98-101.
Some documents in Khara-Khoto's Chinese literature belong to Zhizheng years, Yuan dynasty. There is a puzzling problem. In Yuan dynasty, there were two Zhizheng reign names, which were the reign name of Yuanshizhu Emperor Zhiyuan (1264-1294) and Yuanshundi Emperor Zhiyuan (1335-1340) respectively, and they were called the preZhiyuan and the post-Zhiyuan in the historian circle. And some documents are mostly incomplete in content, so it is difficult to judge their exact age based on the corresponding history. This makes it easy to misjudge the document age.

There are several documents that are suspected to belong to the post-Zhiyuan period in the Heishui literature collected by Britain, which are included in the pre-Zhiyuan period. For example, a document with the No. of OR.8212/736 K.K.0150(a), named as "Report on the arrest of Echiwu by Long Shiying, an official in charge of case files, in 4th Yuan Zhiyuan (1267)", should belong to the post-Zhiyuan period of Yuanshundi Emperor. In the publication of the plate of Marc Aurel Stein's Chinese Literature Obtained by the Third Archeology in Central Asia (non-Buddhism section), its time was noted as the 4th pre-Zhiyuan (1267).

Combined with the relevant historical background, we know that the document mentioned the "Grindhouse", and the setting of grindhouse in the local was after 15th Yuanzhi. Recorded in History of the Yuan Dynasty: in 15th Zhiyuan, two right and left departments were established, and the right department control: ... there are six subjects in the Grindhouse the first is decrees, the second is thieves, the third is reward, the fourth is prohibitions, the fifth is Kanwang, and the sixth is Dousong. ${ }^{7}$ In 23th Yuanshizu Emperor Zhiyuan (1286), the government of the Yuan Dynasty started to establish the Khara-Khoto Explorer house in the Khara-Khoto area. The Khara-Khoto Explorer house was equipped with six rooms, namely, Official Ceremony room, Revenue room, Land Tax room, Grindhouse, Ordnance room and Law room, which are responsible for the management of ritual, officials and soldiers, torture, works, document processing and other affairs. This document is concerning the arrest of criminals by grindhouse, so it should be a matter after the establishment of Khara-Khoto. Therefore, the document should be in the year of 4th postZhiyuan (1338).

The cases are similar to "Zhancican document in 3rd Zhiyuan, Yuan dynasty" with the No. of OR.8212/738 K.K.0150(s) in Marc Aurel Stein's Chinese Literature Obtained by the Third Archeology in Central Asia (nonBuddhism section) and the document of "official document of Lili room in 2nd and 3rd Zhiyuan, Yuan dynasty"8 with the No. of Д X.19070 in Dunhuang Manuscripts in the Russian Collection compiled by Jin Yingkun. Their ages were also mistaken for pre-Zhiyuan period.

For such cases, this paper tries to correct some deficiencies in the predecessors' studies in the document schedules with era name discovered in Khara-Khoto.

Song Lian History of the Yuan Dynasty· Volume Eight-five Zhi Thirty-five [M], Beijing: Zhonghua shuju's revised edition 1976

Jin Yingkun Textual Research on the Heicheng Documents in Dunhuang Manuscripts in the Russian Collection and Discussion on Related Problems[J], The twenty-fourth series of Dunhuang Studies 2003 Page 61-81. 
Next, we will also find a new situation from the specific time of the era name itself discovered in Khara-Khoto, that is, the era name of individual documents are not entirely consistent with that in reality. Here are a few documents that are typical.

For example, the document of "Letters of 6th Jianzhong, Tang dynasty" published in Volume VI of Heishui Documents Collected by Russia, is numbered as И н в .No.5949, and the time in the document is 6th Jianzhong (6th Jianzhong is A.D. 785, and Jianzhong is the reign name of Emperor Tang Dezong, totaling 4 years, that is, from January A.D. 780 to December A.D. 783.). But, actually, A.D. 785 should be the first year of Zhenyuan, Tang dynasty. Tang dynasty changed the emperor's reign name as Xingyuan in A.D. 784, and then changed it as Zhenyuan in A.D. 785. The reasons why KharaKhoto did not know the inland changed its reign name to Yuan and still use Jianzhong, Tang dynasty are perhaps because Hexi and Longyou areas were occupied by Tubo after the An Lushan Rebellion in Tang dynasty and the connection between Khara-Khoto and Central Plains was cut off and people were ill-informed.

However, this situation cannot be fully used to explain the difference between the specific time in an individual document and history reign name in reality. For example, there was a "Pei Songshou's Pawn contract in 13th Tianqing" with a No. of OR.12380-3771.a.1(K.K.II.0232.ee) in Volume V of Heishui Literature Collected by Britain. The time in the document was 13th Tianaing (1206), but Emperor Xiangzong of Western Xia, Li Anquan, changed it to Yingtian, Yuan dynasty after his usurping the throne according to the historical records. Unlike the letters of 6th Jianzhong, Tang dynasty, Khara-Khoto in the Western Xia period was the resident of Yan's military counsel or of Heishui Town, as well as northwest military and political of Western Xia. Combined with the situation at that time, such situation that the isolation of Khara-Khoto and Western Xia hinterland resulted in a poorinformation condition will not exist.

About the issue of reign name mentioned in "Pei Songshou's Pawn contract in 13th Tianqing" of Heishui literature collected by Britain, based on the document interpretation, it can be judged that the generation time of documents should be after "March 21, 13th, Tianqing". With the help of this document, it seemed that we can tentatively speculate that this reign name is indeed used by the locals in the first half of that year, and the time was still slow when the people lived in border area away from back-land received or used the government decrees that Xixia changed the reign title. Of course, the final results and details of such problems need the new materials to solve and still need to be studied on the basis of documents and evidences.

The same cases can be seen in "loan contract of 3rd Yuantong" with a serial number M1·0970[F20:W45], collected in the sixth volume of Heishui Chinese Documents Collected by China. The time of documents are "from January to December, 3rd Yuantong." However, in November of 3rd Yuantong (1335), the emperor Shun had changed Yuan year to Zhizheng. The later ages called this year as "the first year of Zhiyuan" due to the change made by emperor Shun. Compared with Zhiyuan of Yuanshizhu Emperor, it can be named as the first year of post Zhiyuan. It can also be conjectured from the content of this document that because there exists a hysteresis phenomenon when the government decrees of changing Yuan arrived at Yijinailu and was implemented, and the reign name of "3rd Yuantong" was used until the end of year.

Last, the Chinese documents with reign name discovered in Khara-Khoto also have the conditions that the name and age of documents need to be judged.

For example, a document with the No. of OR.8212/1191 KK.0150.rr, named as "incomplete documents of Western Xia”, is issued at Marc Aurel Stein's Chinese Literature Obtained by the Third Archeology in Central Asia (nonBuddhism section). The document is named as "incomplete documents of Western Xia", which may because the reign title in the context are conjectured as Renqing and Tianqing and other Western Xia years. Moreover, the incomplete content and interpretation can provide less value and the judgment for the time of documents can only depend on its reign title. However, in the same period, the Song and Jin Dynasty had used Baoqing, Chongqing and other reign title with Qing (Chinese character), and there are many documents discovered in Huangqing, Yuan Dynasty. Therefore, these documents named as "incomplete documents of Western Xia" seems too early, with the following discover of new materials and deepen textual research, the accurate time may be judged.

\section{The Year Mark and Chronological Title Characteristics of Chinese Literatures with Chronological Titles Unearthed in Khara-Khoto}

Among the Chinese literatures with chronological titles unearthed in Khara-Khoto, there are a few which were marked the year with Chinese zodiacs. This way of marking the year was commonly used by northwest nationalities. For example, in the Khara-Khoto's "Buluhan's concubines' regular rice and flour document" numbered f116: w73 and "Sanggeshili king's regular sheep and wine volume" numbered f116: w546, "dragon year" and "snake year" have appeared many times, and respectively correspond to "The third year of Yanyou" and "The fourth year of Yanyou". This way of marking years has been widely used in Tubo, Mongolia and other northwest ethnic groups. The phenomenon of using Chinese zodiacs to mark years in Khara-Khoto's Chinese documents has been studied and wrote researches by pan $\mathrm{Jie}^{9}$, so I will not repeat it here.

In Khara-Khoto's documents with chronological titles, especially the yuan dynasty documents, there is a phenomenon that seals were engraved with the chronological title and specific date especially for stamping and signing the documents. Typical examples are these: the seal stamping of "The fifth year of Zhizheng" for "Wu Zizhong sued the land files" numbered m1 0611 [ F9: w9 ]; the seal stamping of "The third year of Dade" for "Salijisi land matter volume" numbered $\mathrm{m} 1 \bullet 0612$ [ f116: w10 ] ";the seal stamping of "The third year of Zhizhi" for "Wu Zhengzong the village's

Pan Jie "Marking years with Chinese zodiacs in Hei City's regular share instruments" [ j ], inner Mongolia social sciences 2006 (4). 
warehouse official complaint" numbered $\mathrm{m} 1 \bullet 0757$ [f13: w131];the seal stamping of "The twentieth year of Zhizheng" for "Yexianbuhua stopped the officer and sued "numbered $\mathrm{ml}$ • 0772 [ f209: w53 ]; the seal stamping of "The twenty-ninth year of Zhizheng" for the residue numbered $\mathrm{ml}$ • 1571 [84h f80: w11 $\backslash 1040]$; the seal stamping of "The third year of Dade" for the residue numbered $\mathrm{ml} \bullet 1611$ [f111: w11].

There are still two kinds of situations in the seals of the "Dade, Zhizhi and Zhizheng" years. One is the chronological title and the specific date were both carved into a seal in advance specially for stamping, then it was stamped directly at the end of the literature. Examples include three instruments numbered $\mathrm{ml} \bullet 0611$ [F9: w9], $\mathrm{ml} \bullet 0612$ [f116: w10] and $\mathrm{ml} \bullet$ 1611 [f111: w11]; The other is the chronological title was carved into a seal in advance and it was directly stamped on the literature, but the specific date was written by hand in the literature. Examples include two instruments numbered $\mathrm{ml}$ • 0772 [f209: w53] and m1 • 1571 [84h f80: w11 \1040].

Among the literatures there is one numbered $\mathrm{ml} \cdot 1611$ [f111: w11]. The seal of it is "September, - -, Dade". The same example of this kind of chronological title seal engraved as "-

-" has not yet been found in Khara-Khoto's Chinese literatures. Due to the seriously incomplete document, we are unable to determine the time combining the content. We speculate that this form may mean "The eleventh year of Dade ", which needs to be verified by further studying on Khara-Khoto's related Chinese documents.

\section{CONCLUSION}

The chronological titles in remnants of Chinese literatures unearthed in Khara-Khoto such as the historical printed books and paper currencies can not reflect the exact time characteristics of the literatures. This article has only sorted out Khara-Khoto's Chinese writings, social documents, Buddhist vows and some almanac remnants with chronological titles which are already published and studied by the academia. In addition, there are still some Khara-Khoto's literatures at home and abroad not published, the collection and provenance is numerous, and there is a large number of residual leaves which are difficult to read. Also the Dunhuang documents collected by Russia were mistakenly recorded a lot. The Chinese documents unearthed in Khara-Khoto with chronological titles are inevitably missing or mistakenly understood. With the deepening of the study of Khara-Khoto's documents and the passing of time, they need to be further supplemented and corrected by researchers.

\section{REFERENCES}

[1] British national library, North Minzu University, Shanghai ancient books publishing house. Khara-Khoto's literatures collected by Britain (volume 5) [m]. Shanghai: Shanghai ancient books publishing house. 2010.

[2] Shanghai dictionary publishing house. Sha Zhi, Wu Fangsi.Chinese literatures collected by Stein during the third archaeological tour in central Asian (non - Buddhist part) volume I [m ]. Shanghai: Shanghai dictionary publishing house, 2005.

[3] ST Petersburg branch of the oriental study institute of the Russian academy of sciences,ethnic study institute of the Chinese academy of social sciences, Shanghai ancient books publishing house. KharaKhoto's literatures collected by Russia volume ii [m]. Shanghai: Shanghai ancient books publishing house, 1996. 